\title{
Atuação de doulas no serviço público de saúde
}

\author{
Performance of doulas in the public health service
}

Actuación de doulas en el servicio público de salud

\section{Géssica Larissa Barbosa da Rocha', Mônica Cecília Pimentel de Melo"I , Sílvia Raquel Santos de Morais ${ }^{\mathrm{III}}$, Khesia Kelly Cardoso Matos ${ }^{\mathrm{IV}}$}

Resumo: Objetivo: analisar a atuação das doulas no serviço público de saúde, a partir da visão destas e da gestão em uma maternidade local. Método: estudo qualitativo, descritivo, ancorado na perspectiva fenomenológica existencial de Martin Heidegger, envolvendo quatro doulas e três gestoras. Na análise dos dados foi utilizado a Análise de Discurso. Resultados: os campos de atuação das doulas que emergiram foram atenção primária e hospital, e como principal dificuldade de atuação foi a resistência da equipe médica em aceitar essa cuidadora no cenário do parto. A aquisição de informações pelos profissionais foi apresentada pelas doulas como uma possibilidade de atenuar as dificuldades vivenciadas no ambiente hospitalar. As gestoras reconhecem a importância da doula no processo de parto e nascimento. Conclusão: O estudo possibilitou uma visão ampliada acerca das possibilidades de atuação das doulas no serviço público de saúde.

Descritores: Serviços de saúde; Poder familiar; Parto; Mulheres; Enfermagem obstétrica

\begin{abstract}
Objective: to analyze the performance of doulas in the public health service, based on their vision and management at a local maternity hospital. Method: qualitative, descriptive study, anchored in Martin Heidegger's existential phenomenological perspective, involving four doulas and three managers. In the data analysis, Discourse Analysis was used. Results: the fields of action of the doulas that emerged were primary care and hospital, and the main difficulty of action was the resistance of the medical team to accept this caregiver in the delivery scenario. The acquisition of information by professionals was presented by doulas as a possibility to mitigate the difficulties experienced in the hospital environment. The managers recognize the importance of the doula in the process of delivery and birth. Conclusion: The study provided an expanded view of the possibilities of doulas' performance in the public health service.
\end{abstract}

\footnotetext{
${ }^{\text {I }}$ Psicóloga. Graduada em Psicologia pela Universidade Federal do Vale do São Francisco (UNIVASF). Petrolina, Pernambuco, Brasil. Email: gelabaro@gmail.com Orcid: https://orcid.org/0000-0002-5564-6349

II Enfermeira. Doutora em Educação em Ciências, Química da Vida e Saúde UFRGS/UFSM/FURG. Docente em Enfermagem da Universidade Federal do Vale do São Francisco (UNIVASF). Petrolina, Pernambuco, Brasil. Email: monquinamelo@gmail.com Orcid: https://orcid.org/0000-0003-4029-4886

III Psicóloga. Doutora em Psicologia pela UFES. Docente em Psicologia e Medicina da Universidade Federal do Vale do São Francisco (UNIVASF). Petrolina, Pernambuco, Brasil. Email: silviamorays@yahoo.com.br Orcid: https://orcid.org/0000-0002-8077-5281

${ }^{\text {IV }}$ Enfermeira. Mestre em Psicologia pela Universidade Federal do Vale do São Francisco (UNIVASF). Docente em Enfermagem pela Faculdade de Tecnologia e Ciências (UNIFTC). Petrolina, Pernambuco, Brasil. Email: khesia.matos@gmail.com Orcid: https://orcid.org/0000-0002-87728568
} 
Descriptors: Health services; Family power; Childbirth; Women; Obstetric nursing

Resumen: Objetivo: analizar la actuación de doulas desde su perspectiva y a partir de la gestión en una maternidad local. Método: estudio cualitativo, descriptivo basado en la perspectiva fenomenológica existencial de Martin Heidegger, involucrando a cuatro doulas y 3 gestoras. Para el análisis de datos se utilizó la teoría del Análisis del Discurso. Resultados: los campos de actuación de las doulas fueron el ámbito de la Atención Primaria de la Salud y el hospital, y, como principal dificultad para su actuación se advirtió la resistencia del equipo médica a aceptar esa cuidadora en el escenario del parto. La adquisición de información por parte de los profesionales se presentó como posibilidad para atenuar las dificultades que experimentan en el ámbito hospitalario. Las gestoras reconocen la importancia de la doula em el proceso de parto y nacimiento. Conclusión: El estudio permitió ampliar la visión acerca ampliada acerca de las posibilidades de actuación de las doulas en el servicio público de salud.

Descriptores: Servicios de salud; Poder familiar; Parto; Mujeres; Enfermería obstétrica

\section{Introdução}

Acompanhar a mulher durante o trabalho de parto com o intuito de assisti-la do ponto de vista físico, emocional e afetivo não é uma prática contemporânea inovadora, apesar de ter seus benefícios reconhecidos cientificamente. ${ }^{1} \mathrm{Na}$ realidade, o que se busca no presente é o resgate de uma conduta remota que teve sua origem etimológica na Grécia. A palavra doula que significa "mulher que serve a outra mulher", designa hoje um papel de cuidado não clínico que objetiva oferecer à parturiente um suporte seguro e satisfatório, fornecendo-lhe aconselhamento sobre medidas de conforto, e estimulando a autonomia na evolução do processo de parto. ${ }^{2}$

Assim, ela ganha cada vez mais espaço, por ser profissional com formação científica para atuar no parto normal, por meio de métodos não farmacológicos de alívio da dor, assistência pós-natal e aleitamento materno. Como também, fornecer suporte físico, emocional e informativo contínuo para as mães e seus familiares, e estabelecer vínculo entre a mulher e a equipe de saúde. ${ }^{3}$

Embora de origem antiga, a ocupação desenvolvida pelas doulas e a especificidade de suas funções ainda são quesitos pouco conhecidos pela sociedade em geral. Isso decorre devido ao fato do parto ser visto como hospitalocêntrico, afastando da mulher o processo do partejar e o seu o domínio no decorrer do parto e nascimento. ${ }^{4}$ No Brasil, a atuação das doulas no serviço 
público de saúde encontra-se consideravelmente restrita. Esse empecilho está relacionado às limitações e às barreiras institucionais impostas pelo paradigma biologicista, ainda predominante no atual modelo de saúde. $^{5}$

Aos poucos, e em grande parte, devido ao movimento organizado de mulheres, o governo passou a ter um olhar mais voltado para esse público, desenvolvendo estratégias, tais como, a inserção do Programa de Humanização no Pré-natal e Nascimento (PHPN) que tem como objetivo primordial propiciar a melhoria do acesso, da cobertura e da qualidade do acompanhamento pré-natal, da assistência ao parto e puerpério às gestantes e ao recém-nascido, partindo da perspectiva dos direitos de cidadania. ${ }^{6-7}$

Nacionalmente, tem-se como referência da inserção das doulas na rede pública de saúde, o Hospital Sofia Feldman, em Belo Horizonte - Minas Gerais, que é uma instituição filantrópica de assistência à mulher e ao recém-nascido, usuários do Sistema Único de Saúde (SUS), que prioriza como missão a assistência humanizada. O hospital conta com a presença das doulas na equipe de assistência ao parto desde 1997 com o projeto intitulado "Doula Comunitária”. ${ }^{8} \mathrm{Na}$ Bahia, tem-se como pioneiro na proposta de implementação das doulas no SUS, o Instituto de Perinatologia da Bahia (IPERBA), com a inserção desde 2004 do projeto "Doulas: ajudando a nascer”, que capacitou, com a ajuda das monitoras do Hospital Sofia Feldman, as mulheres selecionadas para essa ocupação. ${ }^{2}$

Diante do exposto, partindo-se da conjectura de que a inserção das doulas no serviço público de saúde é uma possibilidade viável e exequível, fez-se importante compreender quais os enfrentamentos e as possibilidades de atuação dessas mulheres a partir do olhar múltiplo dos gestores de uma maternidade e das doulas. Desse modo, surgem os seguintes questionamentos de pesquisa: como se dá a atuação das doulas no Sistema Único de Saúde, a partir da visão destas e da gestão em uma maternidade local? 
O estudo coopera para que profissionais das diferentes áreas da saúde possam discutir sobre a inserção, a capacitação e a institucionalização da doula no serviço público de saúde, trazendo para essa discussão os profissionais da Região Administrativa Integrada de Desenvolvimento (RIDE) do Polo Petrolina-Pernambuco e Juazeiro-Bahia principalmente, os gestores responsáveis pela implantação de programas e estratégias nas maternidades da região. A relevância do estudo encontra-se ainda na possibilidade de expandir o conhecimento para a população acerca de uma ocupação que apresenta benefícios cientificamente reconhecidos, gerando assim, para além do senso comum, uma visão crítica e embasada, possibilitando, sobretudo às mulheres, uma coparticipação e autonomia nos processos e intervenções que aludem ao seu próprio corpo.

A partir das inquietações expostas, surge como objetivo: analisar a atuação das doulas no serviço público de saúde, a partir da visão destas e da gestão em uma maternidade local.

\section{Método}

Trata-se de um estudo com abordagem qualitativa, do tipo exploratório e descritivo, tendo o referencial ancorado na perspectiva fenomenológica existencial de Martin Heidegger (1889-1976), a qual admite o homem como ser de possibilidades que se desdobram mediante a relação deste no mundo e com os outros, bem como, mediante a própria condição de finitude. ${ }^{9-10}$

A pesquisa foi realizada na RIDE do Polo Petrolina-PE e Juazeiro-BA. ${ }^{11}$ Participaram do estudo quatro doulas sem vínculo empregatício formal com qualquer instituição de saúde, e três profissionais da gestão hospitalar de uma maternidade pública da RIDE, incluindo diretoria médica, coordenação do setor de enfermagem e coordenação da sala de parto normal. Ademais, todos os profissionais convidados a colaborar com o estudo, aceitaram participar.

O material empírico foi coletado no período de dezembro de 2016 a fevereiro de 2017, por meio da entrevista semiestruturada, realizada individualmente, contendo dados 
sociodemográficos e orientada por questões norteadoras para cada grupo de depoentes. Para o grupo de doulas foram as seguintes questões: "Em quais contextos você visualiza a atuação da doula?”; “Como você compreende a atuação da doula no serviço público de saúde?”; “Quais dificuldades você acredita que existem na possibilidade de inserção da doula no serviço público?” "Quais estratégias poderiam ser utilizadas para o enfrentamento dessas dificuldades?”. Entre a gestão, as questões foram: O que você entende por doula? Como você compreende a atuação da doula no serviço público de saúde? Como você definiria o papel da doula dentro da instituição em que trabalha?

Foram critérios de seleção para as doulas: ter concluído o curso de capacitação para doulas com certificação e ter no mínimo uma atuação na referida área. A construção de tais fatores levou em consideração o número reduzido de doulas na região e a formação ainda recente de uma parcela considerável destas. O acesso a essas profissionais ocorreu previamente por meio da aproximação prática em eventos científicos, envolvendo a temática do estudo, utilizando-se a modalidade "bola de neve". Nesse método, os membros de uma determinada população, ligados por alguma característica de interesse comum, são capazes de identificar outros membros, e assim, levar o pesquisador a encontrá-los. ${ }^{12}$ A seleção do grupo representativo do estudo ocorreu pela sua implicação na realidade investigada. À medida que iam sendo indicadas, as pesquisadoras faziam o contato por telefone. Todas as doulas indicadas e contactadas aceitaram participar do estudo.

Os critérios de escolha para a participação dos gestores foram: ter no mínimo seis meses como colaborador na maternidade vinculada e não estar de licença ou afastamento das atividades no período da coleta do material empírico. Uma vez inseridos nesses critérios, a inclusão ocorreu por meio de adesão voluntária dos colaboradores do hospital investigado, utilizando-se uma amostra não probabilística, do tipo intencional, com fechamento por exaustão, na qual, todos os envolvidos colaboraram com a pesquisa. 
As entrevistas com a gestão foram colhidas em suas respectivas salas na instituição à qual fazem parte, durante o turno de trabalho de cada profissional. O local de entrevista das doulas foi em uma sala reservada no Centro de Estudos e Práticas em Psicologia CEPPSI/Universidade Federal do Vale do São Francisco (UNIVASF), sendo ambos os espaços, apropriados para garantia do sigilo e confidencialidade das entrevistadas.

A pesquisa utilizou gravação de áudio e as entrevistas foram transcritas e relidas para não perder características importantes da interpretação, e analisado a partir da Análise de Discurso que consiste em uma técnica para compreender e produzir textos, como também conhecer objetos de estudos nas distintas áreas. Em seguida, se construiu as dimensões ideológicas, e posteriormente, foram construídas categorias com o intuito de auxiliar e dinamizar a interpretação dos relatos..$^{13}$

Para operacionalização desta técnica, todo o texto é percorrido para tentar localizar todos os elementos concretos e abstratos que conduzem a um mesmo bloco de significados. Em seguida, agrupam-se as informações de acordo com os elementos significativos (concretos e abstratos) que somam ou confirmam um mesmo plano de significados para, posteriormente, se apreender os temas centrais para a formulação de categorias empíricas a serem analisadas. ${ }^{13}$

A pesquisa foi aprovada pelo Comitê de Ética da UNIVASF, sob nำ1.869.540, em 15 de dezembro de 2016. Foram respeitados todos os aspectos éticos contidos na resolução 466/2012 do Conselho Nacional de Saúde. Todos os gestores e doulas que aceitaram participar da pesquisa assinaram o Termo de Consentimento Livre e Esclarecido em duas vias. Como garantia para preservar o anonimato das entrevistadas, as participantes foram identificadas pela inicial "EG” (Entrevista com Gestão) e “ED” (Entrevista com Doula), enumerados conforme a ordem da aplicação do instrumento.

\section{Resultados e discussão}


Como perfil dos participantes da pesquisa, verificou-se que os dois grupos de depoentes foram constituídos unicamente por mulheres com idades que variavam entre 29 e 45 anos, sendo três gestoras - uma médica e duas enfermeiras obstétricas - e quatro doulas. Entre as doulas, três delas possuíam curso superior completo e uma estava com o curso superior em andamento, nenhuma possuía vínculo empregatício com instituições de saúde na ocupação de doula. No que se refere ao tempo de atuação na assistência ao parto, entre as gestoras, a média foi de 3,6 anos na instituição à qual estão vinculadas, enquanto a média do tempo de atuação das doulas na ocupação foi de 2,8 anos.

A partir da leitura das entrevistas com doulas e gestoras, tendo como base a Análise de Discurso, emergiram quatro categorias: Inserindo a doula no serviço de saúde: um suporte importante no ciclo gravídico-puerperal; Interferência na hierarquia médica X empoderamento da mulher; O meu dever termina onde começa o dever do outro: as doulas conhecem suas limitações éticas e técnicas? Da idealização para a realidade: é possível inserir a doula no SUS?

\section{Inserindo a doula no serviço de saúde: um suporte importante no ciclo gravídico-puerperal}

O suporte da doula à parturiente tem sido considerado como favorável e significativo, e as características satisfatórias do seu trabalho são expressas por gestantes, membros da equipe multiprofissional e pelas próprias doulas. ${ }^{1}$ No entanto, faz-se necessário conhecer em quais ambientes da rede de atenção à saúde materna infantil sua atuação é factível, e de que modo ela contribui quando inserida nesses espaços.

Foi possível observar nos relatos das gestoras, que todas elas discorreram acerca da inserção da doula na maternidade, sendo tal resultado esperado, uma vez que a instituição da qual fazem parte tem essa acompanhante treinada como membro integrante da equipe de assistência ao parto. Em sua totalidade, as doulas também dissertaram sobre o papel que desenvolvem nesse espaço, o que torna possível afirmar que o hospital é um campo de atuação 
consolidado dessas cuidadoras. Entretanto, um novo campo de inserção e atuação das doulas foi apresentado como possibilidade, tanto por elas, quanto pelas gestoras, sendo este, a atenção primária em saúde.

Os discursos a seguir revelam que a inserção das doulas no ambiente da atenção primária ocorreria por meio das Unidades Básicas de Saúde (UBS) e/ou Unidades Saúde da Família (USF), no período do pré-natal, com o intuito de informar e empoderar as gestantes para um possível parto natural, proporcionando-lhes uma maior segurança e fornecendo uma referência de amparo.

[...] A presença dela [doula] na fase inicial da gestação, eu acho que ajudaria essa mulher a buscar [...] empoderamento. [...] a doula tem papel informativo muito grande pela busca do parto normal. [...] Eu acho que a doula no serviço público deveria fazer parte da atenção básica, ser a doula do bairro, ser a doula daquela unidade. E aí, a mulher, a gestante que entrasse em trabalho de parto, poderia chamar a doula dela. (ED2)

[...] e eu acho que a doula, também nos postos de saúde, na atenção básica, também deveria acontecer, [...] para poder ajudar, para a mulher chegar aqui de uma forma mais segura, sabendo como é o trabalho de parto e não se desesperar ao ponto de achar que tem que fazer um parto cesáreo de qualquer jeito. (EG3)

Como foi exposto pelas doulas e gestoras em suas falas, deparar-se com uma doula nesse ambiente poderia desvelar-se como sendo consideravelmente relevante para a gestante. De modo análogo, e validando as afirmativas, pode-se discorrer que a inserção e atuação da doula na UBS/USF, com base no que é proposto pela Política Nacional de Atenção Básica (PNAB), possibilitaria a essa acompanhante treinada, observar e compreender o contexto subjetivo de cada mulher, disponibilizando informações e promovendo o empoderamento para o parto natural, quando possível. ${ }^{14}$

Alguns autores sugerem que haja um incentivo para que as doulas estejam presentes, não apenas nos hospitais, mas que sejam inseridas nas Unidades Primárias de Saúde para que 
possam construir um vínculo com as gestantes, a fim de facilitar a relação interpessoal, podendo beneficiar na evolução do trabalho de parto e parto. ${ }^{4}$ Já na atenção hospitalar, em ambos os grupos de entrevistadas, a atuação foi apresentada como sendo benéfica à parturiente, auxiliandoa na tomada de conhecimento acerca das alterações ocorridas em seu corpo e, por conseguinte, beneficiando o trabalho da equipe, visto que, diminui a necessidade de intervenções e facilita a evolução do trabalho de parto, além de permitir uma maior mobilidade dos profissionais.

Quando a mulher tem uma doula, ela tem entendimento do que está acontecendo com o corpo dela naquele momento, então, ela faz com que esse trabalho todo, de toda uma equipe, seja um trabalho mais facilitado. (ED1)

A gente fica até mais sossegada quando a doula está aqui, porque tem momentos que a gente vem para o posto, vai examinar outra paciente [...]. Ela já está lá, a gente já confia. Pela prática, pela vivência que ela está tendo aqui, ela já percebe alguns sinais, tipo: "está coroando, venha gente, vai nascer". [...]. (EG1)

Corroborando com os achados, a literatura sinaliza que a parturiente ao ser bem informada sobre o trabalho de parto, pode apresentar uma atitude ativa nesse processo, contribuindo de forma significativa para sua evolução normal. Desse modo, o fato de estarem conscientes do processo fisiológico do parto por meio de cuidados integrais na assistência parturitiva, esclarece dúvidas e fortalece os vínculos. ${ }^{4}$

Uma pesquisa realizada em 2017 com doulas na cidade de João Pessoa - Paraíba apresentou alguns discursos que realçaram a contribuição das doulas para com a equipe profissional. Tais depoimentos mostram profissionais reconhecendo que as doulas auxiliam a mulher a vivenciar o momento do parto, uma vez que elas "explicam, ajudam a fazer força, ensinam como fazer”, diminuindo a ansiedade das pacientes e auxiliando-as a adotar um posicionamento ativo durante o processo, ajudando a equipe na prestação de orientações úteis para a evolução do mesmo. ${ }^{2}$ 
A doula no seu modo de ser-para-os-outros se dispõe afetivamente a acompanhar as gestantes, afetando e sendo afetada por esta e, com isso, coconstruindo vínculos, sentidos. Por conseguinte, alguns autores afirmam que as afetações são inerentes à condição de estarmos vivos, podendo trazer diferentes significações. ${ }^{15} \mathrm{Na}$ relação implicada de solicitude que se estabelece entre doulas e gestantes, percebe-se afetações como paciência, compreensão e consideração pela alteridade. O trabalho da doula consiste em debruçar-se sobre uma mulher que possui recursos próprios e suficientes para parir, fazendo-a reconhecer tal possibilidade. Esta solicitude que se mostra no cuidado da doula foge ao modelo biomédico que determina o nascimento como o fim de um processo e não se coloca para aguardar o tempo do devir. A doula enxerga a mulher como ser-no-mundo-com-os-outros e não como mera reprodutora.

\section{Interferência na hierarquia médica $X$ empoderamento da mulher}

Esta categoria discorre sobre a dificuldade relacional e a resistência da equipe médica em integrar a doula na equipe de assistência ao parto. Tal posicionamento pode estar ligado ao fato dessa acompanhante treinada propiciar à mulher a tomada de conhecimento a respeito de intervenções que aludem ao seu próprio corpo, favorecendo o protagonismo da mulher e tirando o posicionamento cultural médico de detentor do conhecimento.

Não somente as doulas apresentaram a resistência médica como um fator negativo para o desenvolvimento do seu trabalho, mas a própria gestão médica e as enfermeiras obstetras manifestaram em seus discursos o embate que parece haver entre essas duas categorias. É importante ressaltar que o relacionamento da equipe de enfermagem com as doulas foi apresentado por uma gestora como sendo mais eficaz, quando comparado à categoria médica. Seguem os discursos:

A maior dificuldade que a gente tem é a própria equipe médica aceitar isso como fundamental, como importância, como equipe multi. (ED3) 
Muitos colegas tem uma certa resistência, ou fingem que estão achando bom, [...], porque sabem que a doula também traz informação para aquela mulher, e a mulher com informação ela pode criticar uma atitude do médico, ela pode inclusive questionar tecnicamente porque é que o médico está tomando alguma conduta, e aí, muitos profissionais se sentem acuados com isso, se sentem incomodados (EG2)

A partir das experiências relatadas pelas colaboradoras foi possível perceber que um problema que persiste na atuação das doulas é, majoritariamente, de âmbito relacional e não estrutural. Surge, então, o seguinte questionamento, as doulas não adentram as instituições hospitalares por falta de estrutura física que as comporte ou haveria uma oposição provinda daqueles que já estão inseridos nesses espaços para que isso não ocorra de fato?

É preciso esclarecer que no Brasil, o modelo vigente de atenção ao parto é o biomédico, em que os partos são institucionalizados, revestidos por tecnologias duras e intervenções no corpo da mulher e do recém-nascido e o centro das decisões é o profissional médico. Entretanto, as doulas atuam justamente na contramão dessas tecnologias e auxiliam no processo de desconstrução do paradigma biomédico vigente, a partir do manuseio de tecnologias leves de cuidado à saúde. ${ }^{14}$ De modo equivalente aos discursos apresentados, algumas pesquisas indicam que ainda existe resistência, por parte de certos profissionais, com a presença de mais uma pessoa para acompanhar, assistir e dar suporte durante o processo de parir, e isso acaba gerando tensionamentos epistemológicos entre esses sujeitos. ${ }^{1-5}$

Muitos profissionais da saúde encontram-se imersos em um modo de pensar lógico- não de sua compreensão. Esse modo racional de entendimento é denominado por Heidegger de pensamento calculante, no qual a atribuição de sentidos e significados por parte das pessoas envolvidas nos fenômenos é descartada de modo a coisificar as relações e eximir o outro da possibilidade reflexiva. ${ }^{9-10,15}$ 
No campo da assistência ao parto, foram encontradas expressões do pensamento calculante nos processos de homogeneização da mulher, quando esta é vista exclusivamente a partir do grupo de risco em que está inserida (baixo, médio ou alto risco) ou pelas características fisiológicas que lhe conferem ou não a possibilidade de conduzir um parto normal. Deste modo, são desconsiderados fatores tais como: história de vida, rotina, relações sociais, crenças, entre outros, determinando previamente quem é essa mulher e quais são suas possibilidades, bem como a conduta padrão que será utilizada com ela a partir de tal definição.

Nos achados da literatura, pesquisadores afirmam que as doulas estão lutando pelo seu espaço de atuação. ${ }^{5}$ Tal espaço é constituído por barreiras institucionais disputas de poder sobre a dominação de uma assistência, desvalorização dos desejos da mulher e, sobretudo, a ruptura de um modelo anteriormente configurado como fisiológico, que se caracteriza pela assistência não humanizada.

O Conselho Regional de Medicina do Estado de São Paulo, em uma consulta referente à atuação das doulas na assistência ao parto e condições para o exercício da atividade, publicada em 2014, esclareceu que a doula tem livre acesso aos serviços de saúde do SUS, da rede própria ou conveniada. Nesse tocante, estes se encontram obrigados a permitir a presença, junto à parturiente, de um acompanhante e de uma doula durante todo o período de trabalho de parto, parto e pós parto imediato, existindo a possibilidade de multa para quem proibir essas entradas. ${ }^{16} \mathrm{~A}$ partir dessa luta e do ganho de visibilidade, os profissionais diretamente ligados à assistência ao parto se veem na obrigação de discutir a entrada desse novo membro em suas realidades institucionais.

O meu dever termina onde começa o dever do outro: as doulas conhecem suas limitações éticas e técnicas? 
De forma homogênea, gestoras e doulas posicionaram-se quanto à percepção coerente da doula diante de suas limitações técnicas, agindo de maneira ética frente à ocupação. A fala da doula indica que a mesma não executa procedimentos médicos ou aqueles destinados ao profissional de enfermagem. Já o relato da gestora, permite inferir que o papel desta acompanhante treinada é somente de apoio físico e emocional, realizado a partir de sua formação e capacitação, expondo ainda o preconceito de alguns profissionais diante do desconhecimento dessa ocupação e suas atribuições.

Eu não vou fazer toque, eu não vou fazer ausculta, eu não vou fazer nada que fuja da minha função como doula. A minha função é estar lá para servir a mulher, para aliviar as tensões dela, para aliviar o psicológico dela, mas eu não vou fazer nenhuma intervenção. (ED1)

[...] porque o que se pensa muito é que a doula vai lá, que não tem nenhum curso técnico e vai lá para fazer o parto. Na verdade, não é assim, a doula ela tem o papel de apoio, é a mulher que serve outra mulher. (EG2)

De modo convergente aos resultados apresentados, um estudo que revelou a opinião das doulas acerca do apoio emocional oferecido às parturientes, apontou que mais da metade das participantes $(67,8 \%)$, possuíam conhecimento a respeito do papel da doula, definindo-o como sendo de oferecer apoio emocional à gestante, propiciando-lhe maior conforto físico e psicológico. Isto posto, o papel cuidador da doula revela diminuição da ansiedade e do medo do parto, contribuindo para um resultado mais favorável no processo de nascimento. ${ }^{17-18}$

Uma pesquisa realizada em 2019 com doulas em Minas Gerias corrobora que as mesmas vieram para ocupar o espaço que ficou vazio no modelo institucionalizado da assistência ao parto, sendo este, o de permanecer ao lado da parturiente e não para substituir algum profissional da equipe técnica. ${ }^{8}$ Deste modo, pode-se discorrer que a presença da doula deve ser encarada como forma complementar e eficaz para o acompanhamento das mulheres e seus 
familiares durante o trabalho de parto, visto que elas não têm a função de executar procedimentos de enfermagem e, portanto, não haveria porque pensar em desvalorização desses profissionais ou de qualquer outra categoria. $^{2}$

Faz-se importante citar que mesmo a doula possuindo outra formação no campo da saúde que a torne habilitada para prestar assistência, durante o processo de cuidado, ela deve desempenhar apenas seu papel de doula, atuando sempre em conjunto com os demais profissionais da saúde, habilitados para prestar cuidado assistencial à mulher e ao bebê durante o pré-natal, parto e puerpério. Nessa conjuntura, evita-se qualquer situação antiética e ilegal com a equipe que torne o ambiente ameaçador e conflitante. ${ }^{14}$

O cuidado que a doula oferta à mulher foge a uma definição comum do cuidado técnico em saúde (conjunto de conhecimentos orientados visando o êxito de um tratamento específico) e se aproxima de um pressuposto que Heidegger denomina de preocupação. A preocupação ou cuidado (sorge) quando ocorre de modo antepositivo ou liberador, favorece que o outro assuma seus próprios caminhos, que se desenvolva e perceba suas possibilidades. Este movimento é chamado de cuidado liberador, o qual devolve à mulher a sua condição de ser integral, proporcionando que a mulher se expresse livremente em seu modo de ser, manifestando seus medos, desejos e escolhas em uma coprodução de sentidos. De modo contrário, o que se vê tradicionalmente são equipes de saúde acostumadas a tomar decisões pelos usuários, assumindo o lugar destes na tarefa de cuidar de si mesmos. Esta é considerada uma maneira inautêntica de cuidado que, embora seja muitas vezes necessária, corre o risco de dominar e tutelar o outro. ${ }^{9-10,15-18}$

\section{Da idealização para a realidade: é possível inserir a doula no SUS?}

Opiniões divergentes surgiram com relação à possibilidade de inserção da doula no SUS. Entre as doulas, mostra-se que é possível tal inserção, apesar da ressalva de uma delas de que a sua implementação efetiva pode demorar. Uma única doula expressou sua opinião desfavorável 
diante de tal possibilidade, e em discurso, direciona para a própria gestão de saúde a inviabilidade do processo, reconhecendo, no entanto, os benefícios oriundos da presença das doulas.

A inserção dessas cuidadoras no SUS foi apresentada de modo positivo pelas gestoras, sendo que todas elas manifestaram esse posicionamento, apresentando a realidade da atuação das doulas em seu local de trabalho. No discurso da gestora, a mesma aponta para uma possível expansão de um projeto que já se encontra em execução.

Eu acho [...] totalmente viável. [...] ia ser uma coisa muito boa. [...] Mas, eu acho que na área pública vai demorar um bocado a virar realmente uma cultura boa. (ED3)

Eu acho ainda bem inviável. Eu como doula e como já fui gestora de saúde, como profissional de saúde, sei o quanto seria maravilhoso ter doula, é importantíssimo! Mas, eu sei também que não é uma prioridade pro gestor. (ED4)

Eu acho muito viável, apoio [...] tanto eu, quanto a minha equipe, elas enxergam de forma positiva [...]. Eu acho que a gente deveria até expandir. Se a gente conseguir mais pessoas para estarem fazendo esse trabalho voluntário aqui, é um ganho muito grande para gente. (EG3)

É válido ressaltar que na visão das doulas sua possível inserção no SUS se justificaria unicamente pela relevância de seu papel, ou seja, a nível funcional, sendo que somente ED4 apresentou uma crítica que pudesse levar a uma reflexão mais aprofundada: a porta de entrada dessas mulheres, que no caso seriam os gestores das instituições, estaria de fato, aberta para recebê-las?

A partir de um estudo sobre a inserção da doula no SUS, percebeu-se que há poucas evidências científicas produzidas no Brasil acerca da atuação e da inserção das doulas nos serviços de saúde, principalmente no SUS. ${ }^{14}$ Apesar disso, experiências exitosas sobre essa inserção podem ser encontradas nacionalmente, como por exemplo, no Hospital Sofia Feldman, em Belo Horizonte (MG), pioneiro na inclusão destas acompanhantes treinadas na equipe de 
assistência ao parto, ocorrido em 1997, e o IPERBA, com a inserção desde 2004 do projeto “Doulas: ajudando a nascer”, ${ }^{2,8}$

Inserir a doula no serviço público de saúde mostra-se como um ganho, tanto para as instituições, quanto para as mulheres gestantes, uma vez que esta cuidadora auxilia na consolidação das políticas de saúde e também evidencia os direitos que os usuários do SUS possuem. Gestores preocupados em tornar efetiva a proposta de humanização do parto, podem buscar na inclusão da doula um acréscimo benéfico para o acolhimento de suas usuárias, levando em consideração que a inserção das doulas na equipe de saúde, tanto na atenção primária, quanto na média/alta complexidade, não tem um custo financeiro elevado e os aspectos positivos dessas ações sobressaem todos os outros. ${ }^{14}$

\section{Considerações finais}

A realização desde estudo possibilitou uma compreensão ampliada acerca das possibilidades de atuação das doulas no serviço público de saúde. Os achados apontam modos similares de compreensão de doulas e gestoras a respeito da temática proposta, constatando-se que ambos os grupos acreditam que a atuação da doula na Atenção Primária e nos hospitais/maternidades promove benefícios à parturiente e seu acompanhante, aos profissionais envolvidos na assistência ao parto e à própria instituição.

A resistência dos profissionais médicos em agregar a doula no cenário do parto mostrouse como principal empecilho vivenciado por essas acompanhantes treinadas ao desenvolver sua ocupação. É importante salientar que os dois grupos de depoentes reconheceram que as doulas não desempenham nenhuma função técnico-assistencial durante sua atuação, estando esta tarefa direcionada aos profissionais de saúde habilitados para tal.

Ressalta-se que todas as doulas referiram visualizar na busca por informação uma estratégia viável de empoderamento das mulheres, e de mudanças no relacionamento entre 
equipe obstétrica, parturiente e doula. Deste modo, a informação surge como uma possibilidade de atenuar as dificuldades relacionais vivenciadas por essas cuidadoras quando imersas no ambiente hospitalar.

O número reduzido de participantes na pesquisa constituiu-se como uma limitação da mesma, estando tal fator associado à quantidade restrita de doulas na região do estudo, bem como, de maternidades que experiênciam este apoio qualificado. É relevante destacar a originalidade dessa pesquisa na RIDE Petrolina-Juazeiro, uma vez que não foram encontradas publicações sobre o tema nesse território.

A partir desse estudo, sugere-se a realização de pesquisas futuras que possam ser realizadas em distintas regiões do país com a finalidade de comparar os resultados e alargar as compreensões acerca da inserção da doula no SUS, visto ser essa uma possibilidade de fortalecer as ações de humanização em saúde materna e infantil nos diferentes níveis de atenção à saúde.

Compreender quais lugares a doula ocupa ou pode vir a ocupar e o papel que ela desempenha nas instituições que acolhem a mulher durante o ciclo gravídico puerperal auxilia na promoção e efetivação de aspectos inerentes às Políticas Públicas de humanização do prénatal, parto e puerpério que atuam em consonância com os princípios e diretrizes do SUS.

\section{Referências}

1. Ferreira Júnior AR, Barros, NF. Motivos para atuação e formação profissional: percepção de doulas. Physis [Internet]. 2016 abr [acesso em 2019 abr 01];26(4): 1395-1407. Disponível em: http://www.scielo.br/scielo.php?script=sci_arttext\&pid=S010373312016000401395\&lng=en\&nrm=iso\&tlng =pt doi:10.1590/s0103-73312016000400017.

2. Wosniak TC et al. Doulas voluntárias em uma maternidade escola na Região dos Campos Gerais: a visão dos profissionais. Enfermagem Brasil [Internet] 2019 [acesso em 2019 mar 29]; ;18(1);32-41. Disponível em: http://portalatlanticaeditora.com.br/index.php/enfermagembrasil/article/view/2324/pdf doi: 10.33233/eb.v18i1.2324 
3. Herculano TB, Sampaio J, Brilhante MAA, Barbosa MBB. Doulas como gatilho de tensões entre modelos de assistência obstétrica: o olhar dos profissionais envolvidos. Saúde debate [Internet] 2018 julset [acesso em 2019 nov 14]; 42(118):702-713. Disponível em:

https://www.scielosp.org/scielo.php?script=sci_arttext\&pid=S0103-11042018000300702\# doi:10.1590/01031104201811813.

4. Morais JMO, Dantas SLC, Paz BSN, Bezerra SMM. Assistência ao parto e nascimento sob a ótica de puérperas atendidas em uma maternidade pública. Revista enfermagem UFSM [Internet] 2019 [acesso em 2020 jan 14];9(e2):1-10. Disponível em: https://periodicos.ufsm.br/reufsm/article/view/28225 doi:10.5902/2179769228225.

5. Silva RM, Jorge HMF, Matsue RY, Jnuior ARF, Barros NF. Uso de práticas integrativas e complementares por doulas em maternidades de Fortaleza (CE) e Campinas (SP). Saúde soc. [Internet] 2016 jan-mar [acesso em 2017 jul 10];25(1):108-120. Disponível em: http://www.scielo.br/scielo.php?pid=S010412902016000100108\&script=sci_abstract\&tlng=pt doi:10.1590/S0104-12902016143402.

6. Ministério da Saúde (BR). Humanização do parto e do nascimento. Ministério da Saúde. Universidade Estadual do Ceará. Brasília (DF): Ministério da Saúde; 2014. 465p. (Cadernos HumanizaSUS; v. 4). [acesso em 2020 jan 14]. Disponível em: http://www.redehumanizasus.net/sites/default/files/caderno_humanizasus_v4_humanizacao_parto.pdf

7. Humanização do parto. Nasce o respeito: informações práticas sobre seus direitos/Organização, Assessoria Ministerial de Comunicação; Coordenação, Maísa Silva de Melo de Oliveira; Redação, Andréa Corradini Rego Costa e Maísa Melo de Oliveira; Revisão Técnica, Comitê Estadual de Estudos de Mortalidade Materna de Pernambuco. Recife (PE): Procuradoria Geral de Justiça, 2015. 34 p.

8. Lima PO, Pinheiro MP, Miranda JL, Guedes HM, Almeida HF. Compreensão sobre o trabalho da doula em uma maternidade do Vale do Jequitinhonha - MG. Revista Brasileira Saúde Mater. Infant., [Internet]. 2019 jul-set [acesso em 2019 nov 14];19(3):575-580. Disponível em: http://www.scielo.br/scielo.php?pid=S1519-38292019000300569\&script=sci_arttext\&tlng=pt doi:10.1590/1806-93042019000300005.

9. Heidegger, M. Ser e tempo. Tradução por Márcia Sá Cavalcante Schuback. 10 ed. Petrópolis, RJ: Editora Vozes; Editora Universitária São Francisco, 2015.

10. Heidegger, M. Todos nós... ninguém: um enfoque fenomenológico do social. São Paulo: Moraes; 1981.

11. Oliveira SH, Farias EA. A gestão dos resíduos da construção civil no Vale do São Francisco: uma proposta de governança pública como ferramenta de desenvolvimento sustentável. Revista Opara Ciências Contemporâneas Aplicadas, FACAPE, Petrolina, 2019; 9(2):63-77. 
12. Vinuto, J. A amostragem em bola de neve na pesquisa qualitativa: um debate em aberto. Revista Temáticas. [Internet]. 2014 ago-dez [acesso em 2017 jul 10];22(44):203-220.

13. Fiorin JL. Elementos de análise do discurso. São Paulo: Contexto, 2018.

14. Barbosa MBB, Herculano TB, Brilhante MAA, Sampaio J. Doulas como dispositivos para humanização do parto hospitalar: do voluntariado à mercantilização. Saúde debate [Internet] 2018 abrjun [acesso em 2019 dez 12]; 42(117):420-429. Disponível em: http://www.scielo.br/scielo.php?script=sci_arttext\&pid=S0103$11042018000200420 \& \operatorname{lng}=e n \& n r m=$ iso\&tlng=pt doi:10.1590/0103-1104201811706.

15. Braga TBM, Farinha MG. Heidegger: Em busca de sentido para a existência humana. Revista da Abordagem Gestáltic [Internet]. 2017 [acesso em 2017 jul 20]; 23(1):65-73.

16. CREMESP. Conselho Regional de Medicina do Estado de São Paulo. 2014. Consulta n 24.385/2013 [acesso em 2017 mar. 12]. Disponível em: https://www.cremesp.org.br/?siteAcao=Pareceres\&dif=a\&ficha=1\&id=11974\&tipo=PARECER\&orgao=Con selho\%20Regional\%20de\%20Medicina\%20do\%20Estado\%20de\%20S\%E3o\%20Paulo\&numero=24385\&situa cao $=\&$ data $=08-04-2014$.

17. Borja TJ, Freitas WMF, Santos LS, Nascimento BGS, Lima DRA, Silva JCMC. O cuidado prestado por doulas em uma maternidade pública: o olhar das puérperas. Rev enferm Cent-Oeste Min. [Internet] 2018 [acesso em 2019 mar 29];8(e2878):1-11. Disponível em: http://seer.ufsj.edu.br/index.php/recom/article/view/2878/2046doi:10.19175/recom.v8i0.2878.

18. Silva NEK, Sancho LG, Figueiredo WS. Entre fluxos e projetos terapêuticos: revisitando as noções de linha do cuidado em saúde e itinerários terapêuticos. Ciênc saúde coletiva [internet] 2016 [acesso em 2019 mar 29];21(3):843-852. Disponível em: http://www.scielo.br/scielo.php?script=sci_arttext\&pid=S141381232016000300843\&lng=en\&nrm=iso\&tlng =pt doi: 10.1590/1413-81232015213.0857201.

\section{Autor correspondente}

Mônica Cecília Pimentel de Melo

E-mail: monquinamelo@gmail.com

Endereço: Av. José de Sá Maniçoba, S/N, Centro, Petrolina-PE, Brasil. UNIVASF/Colegiado de Enfermagem. CEP: 56304-917 


\section{Contribuições de Autoria}

\section{1 - Géssica Larissa Barbosa da Rocha}

Concepção e planejamento da pesquisa; redação; obtenção, análise e interpretação dos dados.

\section{2 - Mônica Cecília Pimentel de Melo}

Orientação; revisão crítica; ajustes e correções.

\section{3 - Sílvia Raquel Santos de Morais}

Co- orientação; revisão crítica; ajustes e correções.

4 - Khesia Kelly Cardoso Matos

Ajustes e correções.

\section{Como citar este artigo}

Rocha GLB, Melo MCP, Morais SRS, Matos KKC. Atuação de doulas no serviço público de saúde. Rev. Enferm. UFSM. 2020 [Acesso em: Anos Mês Dia]; vol.10 e66: 1-20. DOI:https://doi.org/10.5902/2179769237216 